\title{
El término castillo como topónimo de sitios arqueológicos en Perú ${ }^{1}$
}

\section{The Term Castle as a Toponym of Archaeological Sites in Peru}

\author{
Alcides R. Alvarez Vera \\ Universidad Nacional Mayor de San Marcos, Lima, Perú \\ ORCID 0000-0002-6277-5069 \\ alcides.alvarez@unmsm.edu.pe
}

\begin{abstract}
Resumen
La llegada de los españoles a los Andes centrales en el siglo XVI significó un cambio en todos los aspectos de la vida social, incluido lo lingüístico, que se tradujo en nuevas denominaciones desde el castellano para personas y lugares. La investigación se focaliza en un análisis del léxico constructivo usado en el periodo colonial peruano, caso específico de castillo, y cómo derivó para denominar sitios prehispánicos. En base a la revisión de la fuente escrita colonial, características de castillos europeos y de sitios arqueológicos peruanos con dicha denominación se pasa al análisis de semántica léxica. Finalmente, se concluye que las semejanzas que sirvieron para equiparar a los sitios arqueológicos con los castillos europeos se basaron en la metáfora de imagen, ya que dichos sitios tuvieron otras funciones.
\end{abstract}

Palabras claves: castillo, sitio arqueológico, toponimia, Lingüística Cognitiva, metáfora de imagen

\begin{abstract}
The arrival of the Spaniards to the central Andes in the 16th century meant a change in all aspects of social life, including linguistics, which resulted in new names from Castilian for people and places. The research focuses on an analysis of the constructive lexicon used in the Peruvian colonial period, a specific case of castle, and how it derived to name pre-Hispanic sites. Based on the review of the colonial written source, characteristics of European castles and Peruvian archaeological sites with that name, we proceed to the analysis of lexical semantics. Finally, it is concluded that the similarities that served to equate archaeological sites with European castles were based on the image metaphor, since these sites had other functions.
\end{abstract}

Keywords: castle, archaeological site, toponymy, Cognitive Linguistic, image metaphore

Recibido: 07-02-2021

Aprobado: 13-02-2021

Publicado: I5-07-202I

1 Este artículo se deriva de la investigación de mi tesis de maestría en Lingüística en la Universidad Nacional Mayor de San Marcos. 
El término castillo como topónimo de sitios arqueológicos en Perú

Alcides R. Alvarez Vera

\section{Introducción}

La lengua española desde su llegada a América en el siglo XVI sirvió para tomar posesión, para nominar lugares y personas, para hacerse dueño del entorno; fue pues, una expresión del nuevo poder (Rivarola, 1984, p. 131). Desde entonces las lenguas originarias pasaron a un segundo plano en los nuevos centros de poder colonial, aunque en el habla cotidiana de los indígenas permanecieron en uso, dándose en forma paralela el monolingüismo y el bilingüismo. Poco a poco la lengua española fue reemplazando en muchos aspectos lingüísticos a las otras lenguas presentes, por ejemplo, para el caso de los antropónimos durante el III Concilio límense (1583-1591) se dio un decreto que prohibía a los indios usar los nombres de su gentilidad y superstición y que a todos se les dieran nombres cristianos en el bautismo (Martínez Ferrer, 2017, p. 207). Lo mismo se dio en el caso de la toponimia, las ciudades recibían un nombre que era totalmente hispano, por ejemplo, Trujillo, Ciudad de los Reyes (hoy Lima), Villa Hermosa (hoy Arequipa), o eran mezcla entre español y alguna lengua originaria, por ejemplo, Santa Cruz de Saposoa (hoy Saposoa), Santiago de Miraflores de Saña (hoy Saña).

Las nuevas denominaciones de lugar en lengua española no solo se dieron a nivel estatal mediante fundación de ciudades o creación de divisiones territoriales, también se replicó en nominaciones a diversas formas del paisaje, por ejemplo, el río Santa le debe su nombre a la presencia de la ciudad Santa María de la Parrilla (hoy Santa), perdiendo así su nombre prehispánico. Estas nuevas denominaciones llegaron a un nivel más local, por ejemplo, en muchos lugares de los Andes se repite la palabra portachuelo en lugares de paso entre dos cerros, que hoy equivale a abra, o banda a partes llanos a ambos lados de los ríos, que hoy equivale a margen. Debido a que el territorio central andino tiene una ocupación humana de miles de años se pueden observar como parte del paisaje muchas evidencias materiales de poblaciones pasadas, y eso no escapó a la observación de los españoles, por lo tanto, también les dieron denominaciones.

En el siglo Xvi los españoles que llegaron a Perú mencionan la palabra antigualla para referirse a sitios prehispánicos abandonados desde hacía varios siglos o milenios, pero actualmente no se conoce algún sitio arqueológico que tenga ese nombre, parece que no llegó a ser topónimo. Los españoles vieron como poco a poco se iban abandonando muchos asentamientos indígenas sobre todo debido a la política de reducciones, y pasaban a ser las nuevas antiguallas, presentándose en muchos casos la pérdida del nombre original en lengua aborigen tras lo cual se dieron nuevas denominaciones como ánimas, antival, caserón, castillo, 
corralón, fortaleza, gentilar, paredones, pueblo viejo, con sus respectivas alternancias, siendo castillo uno de los que más casos registra en Perú, por eso el interés en dicho topónimo. Las personas encargadas de dar las nuevas denominaciones lo hicieron usando su conocimiento enciclopédico, con categorías y definiciones provenientes de su lengua, basada en la analogía con realidades propias de su patria lejana. Como topónimo todas las palabras españolas mencionadas responden a una motivación real basada en propiedades físicas del lugar, o una motivación ideal basado en algo conmemorativo (Solís Fonseca, 1997, p. 29), debido a que muchos de los sitios arqueológicos son algo observable, presentes en la superficie, como ya se mencionó. La palabra arqueología surgió en Francia a fines del siglo XVII, a inicios del siglo XVIII se le reporta en Inglaterra usada por los anticuarios, e ingresará al diccionario de la Real Academia Española en su octava edición de 1837, pero eso no fue impedimento para nominar lugares con restos materiales de poblaciones prehispánicas durante los periodos colonial y republicano.

La presente investigación se centra en la parte semántica de la denominación castillo, tiene como objetivo encontrar las razones de la nominación hecha por los españoles para hacer equivalente castillo europeo con edificación indígena andina. El corpus léxico es de una sola palabra, pero que cuenta con casi cincuenta ejemplos en los Andes peruanos, de los cuales se toman tres ya investigados como muestra representativa de función. El articulo comienza con una revisión de la fuente del periodo colonial, así como de la lexicografía editada en España en los mismos siglos. Se ve la etimología de la palabra que, según las fuentes consultadas, nos remite al étimo castrum, palabra latina que denominaba a los campamentos temporales del ejército romano. Se buscan los antecedentes europeos de este tipo de edificaciones que sabemos tienen sus antecedentes en la Antigüedad, pero a partir del siglo XI en Europa se construyeron masivamente con nuevas formas, y con la llegada del Renacimiento decrecieron en importancia, pero quedaron presentes en la imaginación y en el léxico de las personas. También se rastrea el uso de castillo durante el periodo colonial, algo difícil ya que no se construyeron castillos en el virreinato peruano. Para el análisis se toma una muestra representativa de tres sitios, el «castillo de Chavín de Huántar» en la provincia de Huari, el «castillo de San Rafael» en el valle del río Grande (también denominado Chankillo), y el "castillo de Huarmey» cerca de la ciudad del mismo nombre, todos en la región Áncash. Finalmente, de forma breve se mencionan como las investigaciones arqueológicas en dichos lugares han revelado que las funciones que tuvieron dichos sitios en su época de uso no coinciden con los rasgos semánticos de la palabra castillo. 
El término castillo como topónimo de sitios arqueológicos en Perú

Alcides R. Alvarez Vera

\section{Marco teórico}

La presente investigación se aborda desde la perspectiva de la Lingüística cognitiva (LC) que sostiene que la frontera entre conocimiento lingüístico y conocimiento del mundo es artificial, ya que el significado se fundamenta en nuestro conocimiento del mundo y el separarlos oculta aspectos centrales en el estudio de las lenguas (Cuenca y Hilferty, 1999, p. 94). De esta intersección surgen las categorías, que presentan una estructura simbólica, y dichas categorías se agrupan formando dominios que constituyen el conocimiento enciclopédico que cada hablante posee, y a su vez cada categoría llega a tener un modelo cognitivo idealizado (una abstracción con lo más básico que debe tener la categoría), pero como en la realidad existen variaciones las categorías se vuelven radiales. La estructura simbólica tiene un polo semántico que es el significado, el cual muchas veces se origina por el uso de figuras cognitivas como la metáfora, la metonimia, entre otras. A continuación, se pasará a definir todo lo mencionado.

\subsection{Categorización}

Para la LC la categorización sirve para organizar la información del mundo mediante la generalización y la discriminación, lo que produce las categorías conceptuales. La categorización en la LC lleva a distinguir dos partes dentro de cada categoría, un prototipo que ocupa el centro de la categoría, y una periferia, que se aleja de ese centro:

2.1.1 Prototipo: una representación mental relativamente abstracta que reúne los atributos y rasgos clave que mejor representan un ejemplar de una categoría dada (Evans, 2007, p. 175). Es la primera imagen que nos evoca una palabra y que resulta de la interacción de un conjunto de atributos o características (Cuenca y Hilferty, 1999, p. 35). Por ejemplo, un libro que tiene los rasgos de hojas agrupadas con texto escrito, fotos, dibujos, etc con tapa dura, numeración, índice, diagramado en posición vertical.

2.1.2 Periferia: serán todos los demás ejemplares de la misma categoría que no tienen los mejores atributos. Por ejemplo, un libro sin tapa dura, poco texto escrito y más fotos o dibujos, diagramado en posición horizontal.

264 Lengua y Sociedad. Revista de Lingüística Teórica y Aplicada 


\subsection{Estructura simbólica y construcción gramatical}

La LC plantea que la gramática existe, pero la cuestión es la naturaleza de ella y su relación con las otras dimensiones de la estructura lingüística, proponiendo que es simbólica por naturaleza. Se entiende por simbólico el emparejamiento de una estructura semántica y una estructura fonológica de tal forma que uno evoca al otro, y nada más allá de esta estructura simbólica necesita ser invocada. Más específicamente, el lexicón y la gramática forman una gradación consistiendo únicamente en la reunión de estructuras simbólicas (Langacker, 2008, p. 5). Esto lleva a ver al lenguaje como algo simbólico donde el significado es simbolizado fonológicamente, para lo cual una lengua necesita por lo menos tres clases de estructuras: semántica, fonológica y simbólica. Las estructuras semánticas son conceptualizaciones para usos lingüísticos, como los significados de palabras o frases, las estructuras fonológicas incluyen sonidos, gestos y escritura, y las estructuras simbólicas no son distintas de las anteriores, sino que se les incorporan; la estructura simbólica $(\Sigma)$ reside en la unión entre las dos anteriores por lo cual es bipolar, con un polo semántico (S) y otro polo fonológico (P), ilustrándolo con un gráfico, y en base a esta estructura simple se pueden formar estructuras complejas. (Langacker, 2008, pp. 14 y 15)

Siguiendo a Langacker y aplicando lo mencionado a un ejemplo, tendríamos un polo semántico [LIBRo], en el cual está representado el concepto categorizado, y un polo fonológico [libro]. El lexema [Libro] sería el prototipo, con presencia de hojas, cubierta, texto escrito, etc. Sin embargo, hay unidades simbólicas cuya estructura interna no es el resultado de la simple suma de las características de los constituyentes como por ejemplo las expresiones. Para solucionar esto la LC recurre a la construcción gramatical por la cual una estructura puede presentar características no derivadas de sus constituyentes o puede perder alguna característica que éstos poseen, algo aplicable no solo a la semántica sino también a otros ámbitos como sintaxis, morfología, fonética (Cuenca y Hilferty, 1999, p. 69).

\subsection{Dominio cognitivo y conocimiento enciclopédico}

Para la LC el procesamiento del polo semántico de un enunciado activa una o más esferas coherentes del conocimiento llamadas dominios cognitivos, lo que da como resultado la naturaleza inherentemente enciclopédica de la semántica, llegando algunos de los lingüistas cognitivos a postular que no existe una clara 
El término castillo como topónimo de sitios arqueológicos en Perú

Alcides R. Alvarez Vera

línea divisoria entre el conocimiento lingüístico y el conocimiento del mundo. Tenemos dos nuevas categorías:

2.3.1 Dominio cognitivo: son representaciones mentales de cómo se organiza el mundo y pueden incluir un amplio abanico de informaciones o, dicho de otra forma, son ámbitos coherentes de conocimiento que llevan a cabo una función de marco para conceptos más específicos (Cuenca y Hilferty, 1999, pp. 70 y 72). Constituye una estructura de conocimiento coherente poseyendo, en principio, algún nivel de complejidad u organización (Evans, 2007, p. 61). Por ejemplo, las diferentes especies animales domesticados o silvestres se agrupan dentro del dominio cognitivo ANIMAL.

2.3.2 Conocimiento enciclopédico: el cuerpo estructurado de conocimiento no lingüístico al cual una unidad lingüística tal como una palabra potencialmente provee acceso (Evans, 2007, p. 72). Por ejemplo, al pensar o hablar de la llama trae a la mente que vive en zonas altoandinas, ha sido domesticado hace milenios, es herbívoro, lleva carga, etc.

\subsection{Modelo cognitivo idealizado y categoría radial}

Se tiene que tomar en cuenta al dominio cognitivo como algo esencial a la estructura semántica ya que ayuda a contextualizar, ayuda a determinar la lectura pertinente de un término que admite diferentes interpretaciones. Aquí es donde surge la categoría modelo cognitivo idealizado asociada a las anteriores y que es aquel modelo constituido por las expectativas sociales que tenemos acerca de algo, compuesto por el conocimiento enciclopédico (Cuenca y Hilferty, 1999, p. 75). Una representación mental relativamente estable que representa una 'teoría' acerca de algún aspecto del mundo para lo cual las palabras y otras unidades lingüísticas pueden ser relativizadas, pero si bien rico en detalles, está 'idealizado' ya que es una abstracción a través de un conjunto de experiencias en vez de que represente un ejemplo específico de una experiencia dada (Evans, 2007, p. 104).

El modelo cognitivo idealizo choca con casos atípicos, pero es allí donde gracias a las categorías de prototipo y periferia se resuelve el problema. Para el caso de las construcciones con fines religiosos no cristianos el prototipo que los españoles tenían en mente en el siglo XVI eran las mezquitas vistas en la península ibérica, por eso usaron esa palabra para denominar a edificaciones religiosas como Pachacámac.

266 Lengua y Sociedad. Revista de Lingüística Teórica y Aplicada 
Una palabra puede tener más de un sentido, pero interrelacionados, lo cual lleva a la polisemia, que la convierte en categoría compleja, también denominado categoría radial, que es aquella categoría cuyos miembros están organizados con respecto a un prototipo compuesto. Los miembros de una categoría radial no son generados sino más bien extensiones por convención y por eso deben ser aprendidos (Evans, 2007, p. 104). La categoría radial se basa en la semejanza de familia ya mencionado previamente. Un caso que ilustra esto es el de «guaca» que según el diccionario de la Real Academia Española (2020) tiene varios significados que van desde sepulcro de indios con objetos de oro y plata hasta hoyo donde se depositan frutas para que maduren, pasando por alcancía, objetos escondidos en general, etc.

\subsection{Figuras cognitivas: metáfora y metonimia}

La LC también sostiene que los humanos somos seres figurativos, ya que en buena medida nuestro sistema conceptual se organiza en consonancia con una poética internalizada que todos llevamos y esto se refleja en las concepciones figuradas que conducimos diariamente a través del lenguaje. Los procesos figurativos del lenguaje diario no son «meras palabras», son una cuestión de conceptualizaciones (Cuenca y Hilferty, 1999, p. 124). Esto es lo que origina el uso de metáforas, metonimias, hipérboles, e ironías en el habla diaria.

2.5.1 Metáfora: forma de proyección conceptual que incluye proyecciones o correspondencias entre distintos dominios conceptuales (Evans, 2007, p. 136). Por ejemplo, cuando alguien dice «ese señor tiene vista águila», se traslada una característica del águila que es del dominio ANimal al dominio HUMANo.

2.5.2 Metonimia: es un proceso cognitivo en el cual una entidad conceptual, el vehículo, provee acceso mental a otra entidad conceptual, la meta, dentro del mismo dominio, o ICM (modelo cognitivo idealizado por sus siglas en inglés) (Kovecses y Radden, 1998, p. 39). Por ejemplo, cuando se dice «el jefe es duro como el acero», se destaca la dureza que es una cualidad del acero mencionado, no se sale del dominio METAL.

Para ambos casos se mencionan dominios que son relacionados, a veces de uno a otro como en el caso de la metáfora y a veces dentro de uno solo como en el caso de la metonimia. Para la presente investigación interesa solo el primer proceso figurativo. 
El término castillo como topónimo de sitios arqueológicos en Perú

Alcides R. Alvarez Vera

\subsection{Metáfora de imagen y metáfora conceptual}

En la LC se distinguen dos tipos de metáforas:

2.6.1 Metáfora de imagen: son aquellas que proyectan la estructura esquemática de una imagen sobre la de otra, se basa en correspondencias entre facetas perceptivas del dominio de origen y del dominio destino, no en expresiones metafóricas (Cuenca y Hilferty, 1999, pp. 104-105). Una clase de metáfora basada en el recuerdo físico percibido (Evans, 2007, p. 105).

En las metáforas de imagen hay imagen de origen y/o fuente y una imagen de destino y/o meta, pero no hay transferencia de concepto sino de imagen o forma. Según Lakoff las imágenes que la metáfora de imagen aplica son imágenes convencionales adquiridas inconscientemente y automáticamente con el paso de los años por los miembros de una comunidad cultural. En la proyección de una imagen sobre otra hacemos uso de la estructura interna de las imágenes, ambas imágenes deben ser estructuradas en términos de una forma general de la misma clase, las formas deben ser representadas de una manera flexible lo suficiente para que encaje en una proyección de imagen, esto es, las formas deben ser representadas de una manera que sean más topológica que pictórica (topológico en el sentido de generalización sobre formas geométricas especificas) (Lakoff, 1987, pp. 219-222).

2.6.2 Metáfora conceptual: esquema abstracto que sirven para agrupar expresiones metafóricas (Cuenca y Hilferty, 1999, p. 100). La definición de metáfora conceptual nos lleva al concepto de expresión metafórica que es un caso individual de una metáfora conceptual (Cuenca y Hilferty, 1999, p. 100). Por ejemplo, «el tiempo vuela» es una expresión que agrupa el dominio TIEMPo con el dominio VIENTO.

\section{Metodología}

Esta es una investigación de semántica léxica diacrónica en torno al topónimo castillo desde la perspectiva de la Lingüística cognitiva (LC), palabra en su uso durante los periodos colonial y republicano. Los datos presentes en textos escritos publicados de dichos periodos sobre los Andes centrales sirven de corpus para el análisis, se toma una o dos citas textuales procedente de publicaciones de cronistas españoles y de algunos autores del periodo republicano para mostrar el uso de castillo como denominación de edificaciones prehispánicas. 
El análisis rastrea el étimo latino que le dio origen, su evolución a la palabra española castillo durante la Edad Media y su aparición en la lexicografía castellana. Se amplía la parte del periodo medieval en cuanto a la edificación de castilos y sus connotaciones para así conocer el concepto prototípico que tuvieron los españoles en el siglo XVI al llegar a los Andes, para lo cual se consulta diversas publicaciones, así como medios virtuales de internet. Luego, el topónimo es visto como estructura simbólica y construcción gramatical, se muestra la estructura radial que ha llegado a formar a través del paso del tiempo, y como su aplicación en los Andes fue producto de una metáfora de imagen.

\section{Análisis}

\subsection{Corpus: la denominación castillo en textos escritos de los periodos colonial y republicano}

Se registra el uso de la palabra castillo para denominar edificaciones prehispánicas desde los primeros años de la llegada de los españoles a los Andes centrales, pero como menciona Lydia Fossa no es muy común en las crónicas más tempranas que tienen la ventaja de ser las que más cerca estuvieron a las realidades indígenas prehispánicas (L. Fossa, comunicación personal, 18 de julio de 2020), y se le siguió usando en los siglos siguientes para referirse a dichas edificaciones y por extensión al lugar donde se ubicaban. En la lexicografía bilingüe de inicios del periodo colonial se menciona castillo como traducción de pucara, tanto para el caso de la lengua quechua como para la lengua aimara, y como sinónimo de fortaleza. La palabra pucara es préstamo léxico de una lengua del grupo aru (aimara) a la lengua quechua (Fossa, 1989, p. 47).

El cronista Pedro de Cieza de León publicó en 1553 la Crónica del Perú donde menciona:

...Sin esto por los cerros y collados altos tenían castillos y fortalezas desde donde por causas muy liuianas, salían a darse guerra vnos a otros, y se matauan y castiuauan todos los mas que podían... vnos a otros se dauan grandes guerras, y se cometían muchas muertes y robos: y passaron por vnos y por otros grandes calamidades, tanto que se destruyeron muchos castillos y fortalezas... (1984, pp. 123-124. Cursivas agregadas) 
El término castillo como topónimo de sitios arqueológicos en Perú Alcides R. Alvarez Vera

En su obra El señorío de los Incas (1553), que permaneció inédita hasta fines del siglo XIX, anota:

...Otros hazían en los serros castillos que llaman pucarais, desde donde, aullando con lenguas estrañas, salían a pelear unos con otros sobre las tierras de labor... con todo lo qual, yvan trufando a lo alto de los çerros donde tenían sus castillos y allí hazían sus sacrefiçios a los dioses... (Cieza de León, [1553] 1985, p. 6. Cursivas agregadas)

El cronista Miguel Cabello de Balboa usa la palabra castillo en su obra Miscelánea antártica ([1586] 1951) cuando trata sobre hechos históricos en el Viejo Mundo y las palabras fortaleza y encastillado cuando se refiere a la historia andina prehispánica. Al mencionar la guerra de Yngayupangui en el Chinchaysuyo escribe:

... Paso de allí á la Provincia de los Angaraos donde alló resistencia en los naturales, y hechos fuertes en una fortaleza de Orcolla, y Guaila Tucara, ... y al cabo de algunas escaramuzas, y recuentros vino a manos de los de el Cuzco, y en ella murio mucha gente de la encastillada en la fortaleza y fue preso su Cacique... (p. 319. Cursivas agregadas)

El jesuita Bernabé Cobo menciona varias veces la palabra castillo en su obra «Historia del nuevo mundo» publicada en 1653:

...Habiendo este rey [Pachacutic] acrecentado su imperio con tantas y tan dilatadas provincias, se dio en lo que le quedo de vida a ilustrarlas con edificar en los principales pueblos dellas magnificos templos y palacios y algunos fuertes castillos al modelo de los edificios que habia visto en Tiaguanaco, como son los edificios de Vilcas, del Huarco, de Limatambo y la gran fortaleza del Cuzco; en suma, las mas suntuosas fabricas que hubo en este reino, cuyas ruinas duran todavía... ([1653] 1892, p. 166. Cursivas agregadas)

Como se verá más adelante, algunos de los sitios arqueológicos investigados con el nombre castillo tuvieron diferentes funciones que no corresponden a la función militar como en la Europa medieval. En el virreinato del Perú hubo títulos nobiliarios de conde, duque, marques, y vizconde, pero esa nobleza indiana vivía en casas en las ciudades. Durante el periodo colonial peruano no se construyeron castillos, las fortificaciones fueron pocas, al igual que el amurallamiento de centros

270 Lengua y Sociedad. Revista de Lingüística Teórica y Aplicada 
urbanos, solo en las ciudades costeras debido a la amenaza de corsarios y piratas (Bustamante, 2001, p. 56).

Para el siglo XIx la palabra ya es usada para nominar edificaciones prehispánicas abandonadas. Mariano Eduardo de Rivero al mencionar su viaje por la sierra central anota:

Desde el pueblo de Chavinillo comienza un sistema de fortificaciones ó castillos, como se llaman por estos lugares, situados en ambos lados de la quebrada... El primer castillo que visité por esta parte, fué el de Masor... (De Rivero, 1841/1994, p. 111. Cursivas agregadas)

Antonio Raimondi (1873/2006) a su paso por la ciudad de Casma en el departamento de Áncash visitó un sitio con dicho nombre:

En varios puntos de la quebrada de Casma se observan, al pie de los cerros, ruinas de los antiguos habitantes del Perú; pero un monumento importante es el llamado Castillo, situado sobre un morro en la banda izquierda del río, a tres leguas de la población de Casma y a media legua de la hacienda de San Rafael o Malpaso... (p. 186. Cursivas agregadas)

De igual manera, a su paso por Chavín de Huántar el mismo Raimondi menciona su visita al sitio arqueológico al que ya se le denominaba castillo:

... Los preciosos restos de la antigua civilización de los incas es lo único que llama la atención; éstos son conocidos en Chavín con el nombre de Castillo... (p. 250. Cursivas agregadas)

Para los siglos xx y xxI, la palabra castillo continuará en uso debido a su polisemia, y como denominación de sitios arqueológicos aparece muchas veces en las publicaciones de investigaciones arqueológicas, por ejemplo, para el caso del «Castillo de Huarmey» se puede citar al arqueólogo cubano Ernesto Tabio quien exploró el lugar en la primera mitad del siglo xx y menciona «área del Castillo... comprendida por los restos de dos pequeños poblados y 4 cementerios huaqueados, así como por un cerro con estructuras de adobe...» (Tabio, 1977, p. 120). 
El término castillo como topónimo de sitios arqueológicos en Perú

Alcides R. Alvarez Vera

\subsection{Análisis lingüístico}

\subsubsection{El castrum romano como étimo}

Según el diccionario etimológico de Joan Corominas la palabra castillo reporta su primera mención escrita en el año 972 proviniendo del latín castěllum, que en dicha lengua significaba «fuerte, reducto», y que era diminutivo de castrum que a su vez significaba "campamento fortificado", «fortificación». De castrum también derivará castro, reportado hacia 1313 con el mismo significado de la palabra latina, y su derivación «castrense» (Corominas, 1987, p. 138).

En el Imperio Romano el castrum tuvo función ofensiva y defensiva, abarcaba de 20 a 25 hectáreas, ubicado en lugares con acceso a buenas comunicaciones por tierra y por medios acuáticos (muchos estuvieron al lado de ríos navegables), tenía diseño rectangular de esquinas curvas, con cuatro subdivisiones al interior en base a dos calles principales que se cortaban en ángulo recto y que llevaban a cuatro puertas abiertas en el muro perimétrico, al interior tenía barracones para alojamiento de soldados (tiendas o chozas de las legiones), almacenes para pertrechos y provisiones, un espacio administrativo, un hospital, termas, etc, y murallas que se hacían en base a troncos de árboles colocados verticalmente uno al lado de otro y con el extremo superior en punta con un camino de ronda, más un foso excavado alrededor de todo el perímetro por fuera, excepto en las entradas, mientras que la permanencia podía ir de varios meses a varios años e incluso décadas (Subirats Sorrosal, 2013, pp. 32-40).

\subsubsection{Origen y evolución semántica de la palabra castillo}

Entre los siglos V y vi se dieron las invasiones bárbaras y el surgimiento del reino visigodo en la península ibérica, para inicios del siglo vin se produjo la invasión árabe y casi toda la península cayó bajo su dominio en menos de un siglo, excepto la parte norte donde se formó el reino de Asturias. La expansión hacia el este del reino de Asturias incorporó el territorio llamado Bardulia a mediados del siglo viII el cual fue reiteradas veces tratado de recuperar por los musulmanes, lo que obligó a levantar un complejo sistema defensivo e hizo derivar con el paso del tiempo el cambio de nombre a Castilla, «país de castillos» (Barroso et al., 2013, p. 11). Es sabido por un documento leonés del siglo ix que la designación original fue Castella, y que los castillos de aquel entonces no eran como los monumentales que se construirían uno o dos siglos después (Alatorre, 1995, p. 94). Paralelamente 
va surgiendo una clase alta conformada por duques y condes que para estos siglos eran de carácter administrativo y no honoríficos, ya que eran gobernadores de un territorio con amplias facultades militares, gubernativas y de administración de justicia, mientras que los marqueses surgirán por influencia francesa debido a la creación de la «marca hispánica» en Cataluña (Mayoralgo y Lodo, 2007, p. 17).

Al llegar el siglo ix los condados cristianos se habían hecho hereditarios en la práctica, según el modelo habitual en el Occidente cristiano, mientras que los pequeños señores tienden a afincarse repartiéndose el territorio en castellanías (Menéndez Pidal, 2015, pp 31-32). La castellanía tuvo dos significados en la Edad Media, la primera como el distrito o territorio que abarcaba la jurisdicción de un alcaide de castillo, y la segunda como la dignidad de alcaide de los castillos, también llamado castellano, que podía ser de carácter real o señorial (Real Academia Española, 2020a). Los castillos de estos primeros siglos, sobre todo en el norte de Europa, consistían en una torre, muchas veces realizada de madera, sobre una colina artificial llamada «mota», rodeada por una empalizada. En ellos residía el líder militar y, en caso de ataque enemigo, la población ingresaba dentro de su estacada y se preparaba para la lucha (Bermón, 2006, p. 60).

A partir del siglo XI en Europa se construyeron castillos masivamente con nuevas formas y con nuevos materiales (Kostof, 1995, p. 299), se reemplaza la madera por piedra canteada, pero se mantiene la ubicación en lugares fácilmente defendibles como cima de colinas, algunos castillos consistían de una torre sin murallas con varias plantas para almacenes y alojamiento de la tropa, otro tipo era el castillo señorial, edificio fortificado pero sin murallas, con puerta en altura a la que se accedía mediante una escalera retráctil, y finalmente el castillo amurallado que tenía varios edificios dentro (Bermón, 2006, p. 61). Para ser considerado castillo debe tener básicamente murallas, torre habitable («torre de homenaje») y un patio de armas (Arteguias, 2001).

Entre los siglos XIV y XV los enfrentamientos entre reyes y señores feudales y las guerras entre reinos incrementaron más la construcción de castillos, con novedades constructivas, e incluso algunos se rodearon de viviendas que terminaron siendo ciudades (Bermón, 2006, p. 62). En la Edad Media también se originaron otras palabras derivadas de castillo como el ya mencionado castellano, que nombraba al hombre que recibía un castillo como beneficio por el vasallaje que tenía con el rey o con un señor (Real Academia Española, 2020b), castellería o castellaje que era la prestación personal para reparar murallas y defensas de fortalezas reales, así como la vigilancia desde las murallas, y también los resanes 
El término castillo como topónimo de sitios arqueológicos en Perú

Alcides R. Alvarez Vera

mencionados en villas a cargo de los concejos, y a medida que pasó el tiempo fue sustituida por pagos económicos (Real Academia Española, 2020c).

A diferencia de los otros países europeos los castillos españoles comienzan siendo propiedad real ya que son botín de guerra y cedido su gobierno a alcaides o tenentes, y a órdenes militares para la protección de un territorio amenazado por la cercanía de Al-Andalus. Entre los siglos XIV y Xv los reyes ceden castillos a familias nobiliarias que reformarán castillos o construirán otros nuevos como palacios residenciales. Por último, a partir del reinado de los Reyes Católicos y la concentración de su poder, multitud de castillos son destruidos coincidiendo con el final de las insurrecciones nobiliarias. Los castillos construidos en España son más bien pequeños, aunque hay excepciones de grandes dimensiones (Arteguias, 2001).

\subsubsection{La denominación castillo en la lexicografía de la península ibérica}

El Corpus del Diccionario histórico de la lengua española (CDHLE) da citas del uso de castillo en la lengua española desde el siglo XIII con el significado de construcción fortificada (Real Academia Española, 2013). En la base de datos del Nuevo Tesoro Lexicográfico de la Lengua Española (NTLLE) se registra la presencia de castillo en el diccionario español-latín de Antonio de Nebrija publicado en 1495:

Castillo villeta cercada. castrum. í.

Castillo pequeño. Castellum. í. (Real Academia Española, 2021)

El Tesoro de la lengua castellana de Sebastián de Covarrubias de 1611 tiene la entrada léxica «Castillo, y León» que da como primera acepción un juego con una moneda, y seguidamente menciona dentro del mismo texto «encaftillar $\int e$, hazer $\int e$ fuerte en algun lugar» (Covarrubias, 1611, p. 210r). Previamente, por orden alfabético, menciona «Castellano... el alcaide a cuyo cargo eftá el castillo» como segunda acepción, y también «Castillejo, caftillo pequeño...» (Covarrubias, 1611, p. 209v). Más adelante en la entrada «Fortaleza» anota «cafa, o caftillo fuerte. Fortalecer, fortificar y hazer fuerte algun Jitio o caftillo...» (Covarrubias, 1611, p. 411v).

En el siglo XviI se publica el Diccionario de Autoridades en cuyo segundo tomo hay seis entradas léxicas para «castillo», siendo la primera la que interesa:

CASTILLO. f. m. Lugár fuerte, cercado de murallas, baluartes, fo $\iint o s$ y otras fortificaciones... (Real Academia Española, 1729, p. 224). 
Para el caso de Fortaleza hay cinco entradas, la última hace referencia a edificación, pero ya no menciona «castillo»:

FORTALEZA. Se llama tambien qualquier lugár bien flanqueado y defendido. Divide e en regular e irregular. Fortaleza regular es la que tiene todos Jus lados y ángulos iguales: Irre gular la que tiene los lados o ángulos de iguales... (Real Academia Española, 1732, p. 738).

Entre las acepciones de castillo en el DLE desde el siglo XVIII hasta la actualidad no se menciona edificación prehispánica andina, pero sí castillo de fuego, castillo de naipes, como parte de barcos, como caseta colocada sobre elefantes, etc.

\subsubsection{Prototipo y periferia de castillo en los españoles venidos al Perú en el siglo XvI}

En España hay inventariados poco más de 10 mil castillos, pero se calcula que hay unos 20 mil. Los castillos en la península eran pequeños en comparación con los del resto de Europa, pero en todos los casos pertenecen al dominio de la edificación, y en base a todo lo anotado previamente se puede plantear que el prototipo tiene como rasgos definitorios el tamaño grande en comparación con una casa, presencia de arquitectura defensiva (murallas, torres, fosos, etc.), ser vivienda de un determinado grupo social y un grupo de soldados con su logística, con una jurisdicción a su cargo, ubicados en la cima de elevaciones del terreno (castillo roquero, castillo de mota), o en terreno plano (castillo de llanura, castillo urbano), o en playa (castillo de bahía), quedando los castillos sin murallas y las torres fortificadas en la periferia. Un ejemplo de castillo español es el de Loarre en Huesca (Figura 1). 
El término castillo como topónimo de sitios arqueológicos en Perú

Alcides R. Alvarez Vera

\section{Figura 1. Castillo Loarre en Huesca}

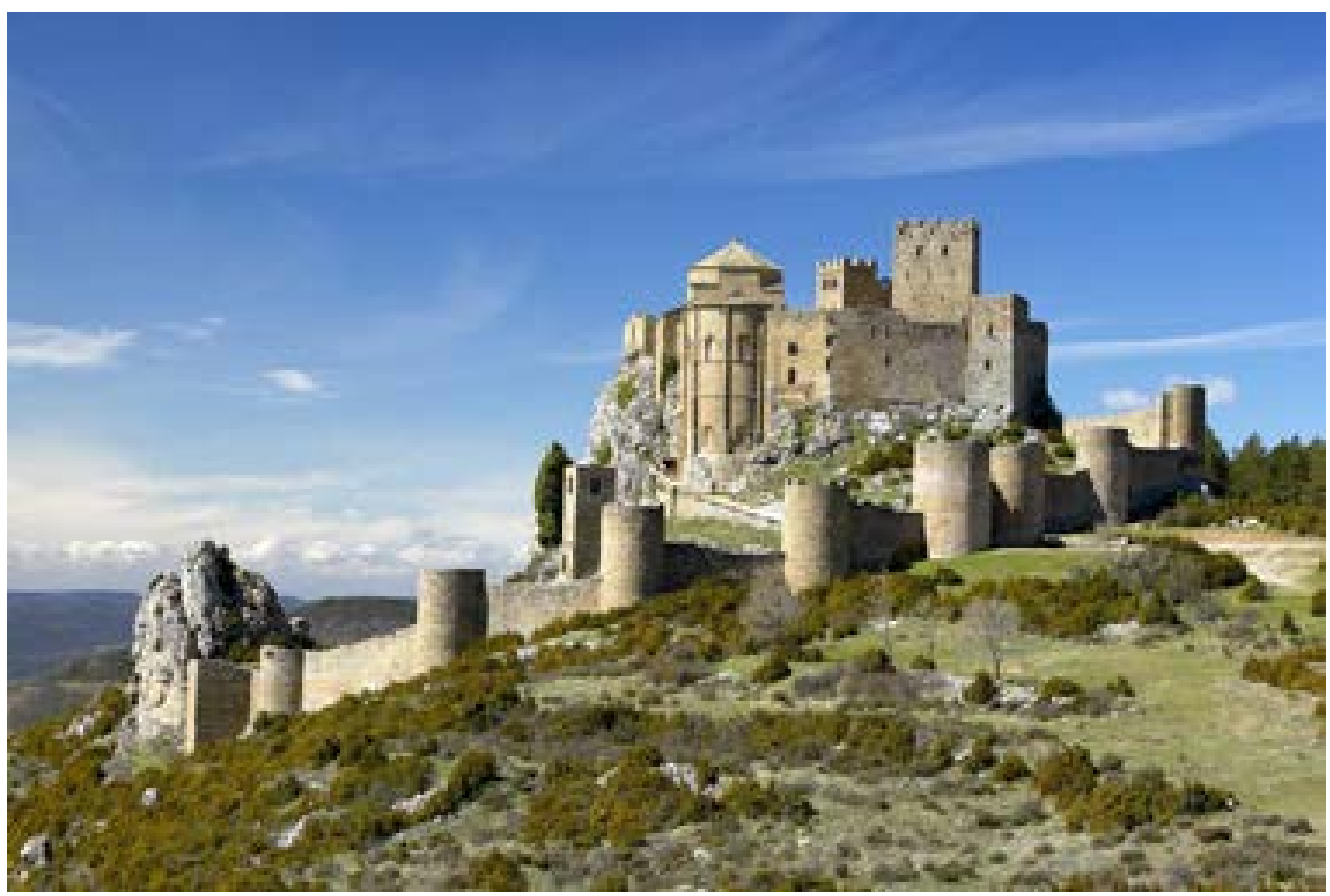

Fuente. Turismo de Aragón (s. f.)

Los cronistas y autores de lexicones provenían de localidades con muchos castillos los cuales vieron en su niñez y adolescencia, y esa experiencia pasó a ser parte de su conocimiento enciclopédico. Todos ellos debieron ser conscientes que estaban ante realidades distintas, pero existía la necesidad de nombrar la realidad observada por lo cual apelaron a la palabra castillo, y en algunos lugares adoptaron el préstamo léxico pucara, lo cual generó alonimia.

\subsubsection{Estructura simbólica y construcción gramatical}

Como se mencionó en el marco teórico la estructura simbólica $(\Sigma)$ reside en la unión de un polo semántico $(\mathrm{S})$ y otro polo fonológico $(\mathrm{P})$. Aplicando lo mencionado a la presente investigación tendríamos un polo semántico [CASTILLO], en el cual está representado el concepto categorizado, y un polo fonológico [castillo]. El lexema [CASTILLO] sería el prototipo, con todos los rasgos mencionados anteriormente. En base a esta estructura simple se pueden formar estructuras con características no derivadas de sus constituyentes que para el presente caso serían 
los nombres específicos de los sitios arqueológicos con la palabra castillo, por ejemplo el Castillo de San Rafael en el valle de Casma, el cual no significa que el santo Rafael es el dueño de la edificación sino que es un nombre de lugar donde San Rafael es la hacienda (hoy desaparecida) en cuyos límites se ubica la edificación denominada como castillo.

\subsubsection{Castillo como categoría radial}

La palabra castillo durante la Edad Media originó otras palabras con forma y significado relacionados mediante derivación y flexión: varios sustantivos (castellanía, castellano, castillaje, castillejo), un topónimo (Castilla), y por lo menos un verbo (encastillar). A partir del siglo xvi la palabra adopta un nuevo significado al innovarse el uso como nombre de edificaciones prehispánicas andinas por una cuestión pragmática entre los españoles en el virreinato peruano y luego en todos los hablantes del castellano andino, alternando con fortaleza. Con el paso del tiempo, el nombre se convirtió en topónimo al igual que fortaleza y pucara, dándose casos de alónimos como se indicó anteriormente. Para el siglo XVIII la palabra en sí ya era polisémica por los varios significados que se reportan en el diccionario de autoridades, muchos de los cuales continúan hasta el presente, pero la acepción que mencione edificación prehispánica debido a su uso en los Andes no es recogida por el diccionario de la academia. Son un total de doce significados mencionados por el Diccionario de la Lengua Española (DLE), a los cuales se tendría que agregar el significado de edificación prehispánica a pesar de su uso en los Andes, por lo cual pasa a ser el significado número trece. Estos significados son los siguientes: 1) lugar fuerte, cercado de murallas, baluartes, fosos y otras fortificaciones; 2) estructura de madera, en forma de torre, antiguamente usada en la guerra, montada sobre animales; 3) maestril, celdilla dentro del panal; 4) cabida de un carro, desde la escalera hasta lo alto de los varales, que es donde va el cochero; 5) rimero de tablas, esto es, una sobre otra no necesariamente ordenadas; 6) en Heráldica es figura que representa una o más torres, en este caso unidas por cortinas; 7) parte de la cubierta alta o principal del buque, comprendida entre el palo trinquete y la proa; 8) cubierta parcial que, entre el palo trinquete y la proa, tienen algunos buques a la altura de la borda. El diccionario de la academia también recoge expresiones que se numeran siguiendo la anterior: 9) castillo de fuego, armazón vestida de varios fuegos artificiales; 10) castillo de popa, sinónimo de toldilla que es el grupo de habitaciones para los oficiales en la popa del 
El término castillo como topónimo de sitios arqueológicos en Perú Alcides R. Alvarez Vera

barco; 11) castillos en el aire, ilusiones sin fundamentos; 12) castillos de naipes, confiar en lograr algo con medios ineficaces (Real Academia Española, 2020d).

Entonces, castillo es una categoría compleja que forma una red semántica partiendo desde el significado prototípico y se extiende a significados menos representativos. Se plantea un modelo de red radial para castillo que tiene en cuenta la numeración del significado según el DLE donde el significado prototípico va con el número 1 y los significados periféricos van con los números 2 al 13, siendo el último el correspondiente a sitio arqueológico, por lo cual se le resalta (ver Figura 2).

Figura 2. Red radial de la palabra castillo

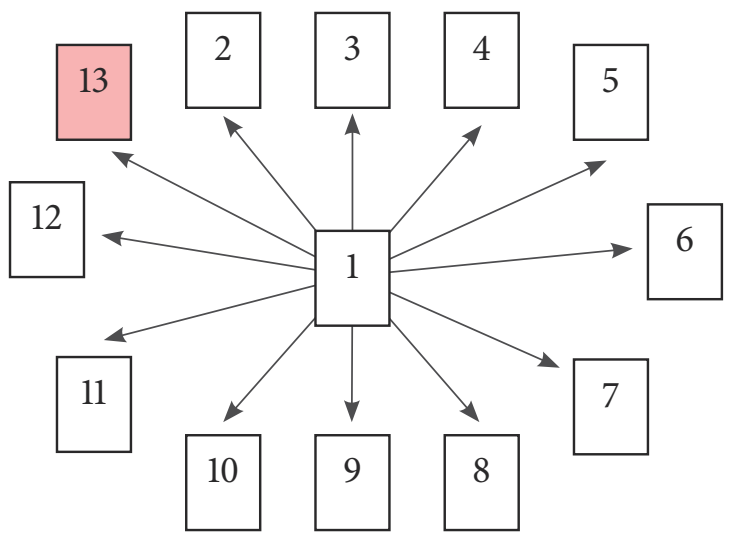

\subsubsection{Metáfora de imagen en el uso de la palabra castillo}

Teniendo definido el prototipo de castillo que trajeron los españoles en el siglo XVI, lo que ellos hicieron fue aplicar una metáfora de imagen ya que al ver los edificios prehispánicos aún en uso o ya abandonados se activaba el recuerdo de lo visto y vivido en la península ibérica. Una característica de toda metáfora es que se proyectan determinados rasgos relevantes de un dominio a otro, en este caso principalmente se proyectaba una imagen mental en otra, donde la forma era el rasgo fundamental dejando de lado los otros rasgos que implicaba esa categoría, como la asociación a una realeza o a una nobleza, o la presencia de una guarnición militar, etc.

Tenemos un dominio de origen que es el castillo español que se recordaba, y un dominio meta constituido por el edificio prehispánico que se observaba. El 
castillo fue parte del dominio edificación durante la Edad Media en la península ibérica que también incluía otros tipos de construcciones. Si lo vemos desde la teoría del eje de categorización vertical el nivel básico lo ocupa el castillo teniendo como nivel subordinado a las diferencias en cuanto ubicación (castillo roquero, castillo urbano, castillo de bahía, etc.), y el nivel superordinario sería el de las edificaciones del cual castillo es un tipo al lado de catedral, monasterio, convento, cárcel, palacio, fortaleza, casa, etc.

Entre castillo y fortaleza hay límites difusos, tienen muchas coincidencias en sus rasgos sémicos, como el tamaño grande, construcciones defensivas, parece que la diferencia es la presencia de la torre de homenaje dentro del castillo que era donde residía el señor feudal. Quizás esto último señalado haya sido la causa de su poco uso y que se haya preferido usar fortaleza por la mayoría de cronistas ya que ella es totalmente militar, no alberga residentes de alto estatus, solo la guarnición militar. Este límite difuso explica el por qué hay muchos sitios arqueológicos con ambos nombres (alonimia), por ejemplo, en el valle y provincia de Casma en Áncash, al sitio arqueológico denominado «castillo de San Rafael» también se le ha llamado «fortaleza de Chankillo».

En el caso de la edificación prehispánica para el siglo Xvi tenemos una tipología variada en pleno uso en aquel momento que incluía templos, palacios, local para guarnición militar, viviendas, posadas para el personal de correos, almacenes, andenería, etc., con presencia de ciudades y aldeas unidas por redes de caminos, que obviamente tuvieron sus respectivos nombres en lenguas originarias. También eran visibles en aquel momento muchas construcciones de siglos y milenios anteriores que respondían a varias de las categorías mencionadas. De todas estas edificaciones solo los que tenían una forma aproximada al castillo ibérico eran a los que se les proyectó la imagen de castillo y por consiguiente la denominación, no importando cuál era su función original, y con el paso del tiempo dicha denominación se extendiera al lugar donde se ubicaba el edificio.

Consultando por internet el Servicio de Información Geográfica De Arqueología (SIGDA) del Ministerio de Cultura, así como diversas publicaciones arqueológicas, se conoce un total de cuarentainueve sitios arqueológicos con el nombre castillo ubicados en diferentes regiones (Ministerio de Cultura, 2021). De todos esos sitios arqueológicos algunos ya cuentan con investigaciones que definen su función, se mencionarán tres:

- Castillo de Chavín de Huántar: ubicado en una llanura en la confluencia de los ríos Mosna y Wacheqsa en Áncash, conocido desde el siglo XVI en la fuente 
El término castillo como topónimo de sitios arqueológicos en Perú

Alcides R. Alvarez Vera

escrita, de muros altos que parecen murallas, pero sin torres ni otras características (ver Figura 3). Las investigaciones arqueológicas señalan que fue un templo de una antigua religión, algo ya mencionado por los españoles a inicios del periodo colonial, que tuvo varias fases constructivas, con galerías subterráneas, que recibía peregrinos de diversas partes de los Andes centrales hace 3000 años (Lumbreras, 2007, p. 19).

Figura 3. El castillo de Chavín de Huántar

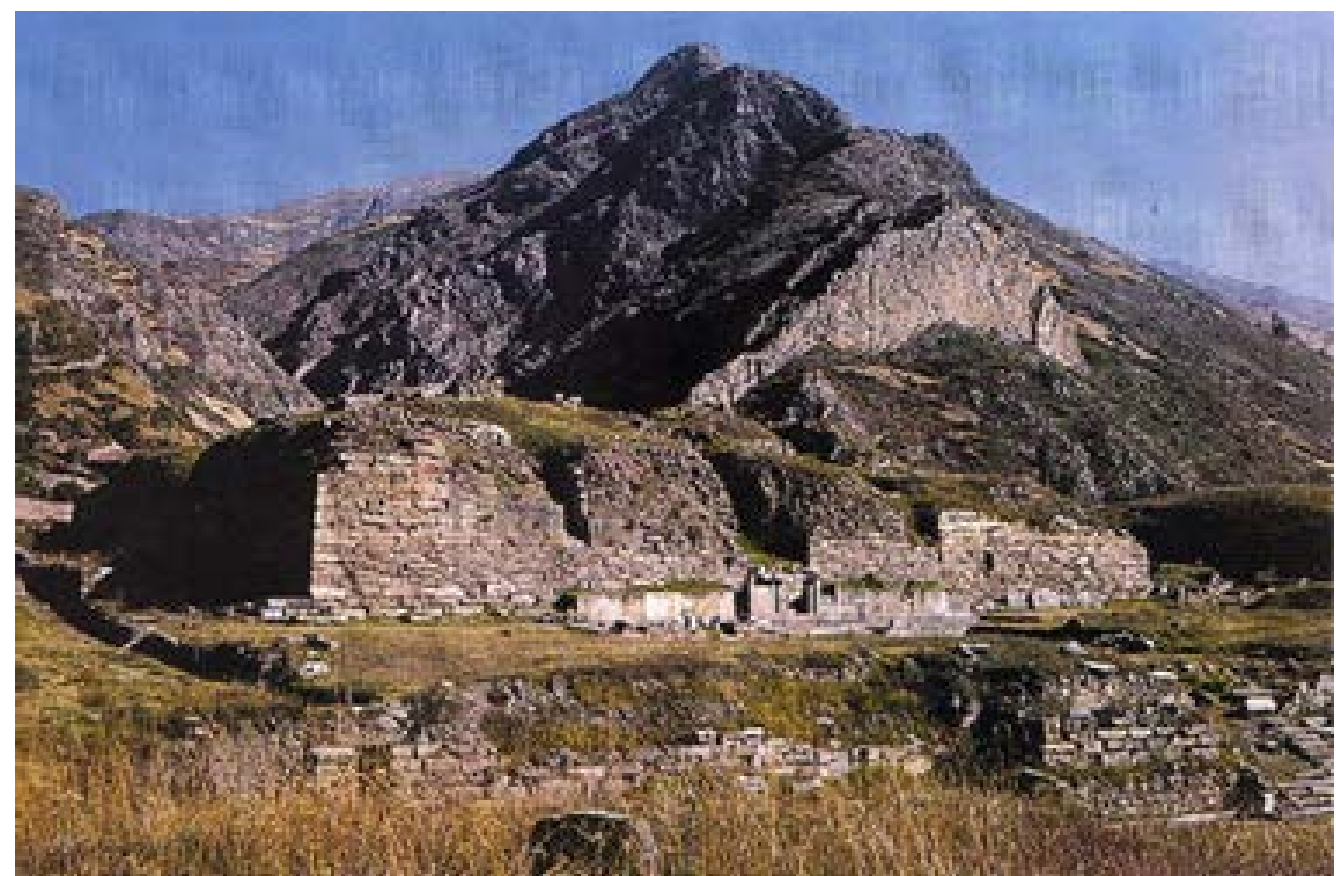

Fuente. Lumbreras, 2007, p. 49.

-Castillo de San Rafael: conocido también como Chankillo, edificación ovalada ubicado en la cima de un cerro en la margen izquierda del río Grande en la provincia de Casma (Áncash), mencionado desde mediados del siglo XIX en diversos libros, con dos murallas que rodean una plataforma central donde hay dos edificios circulares altos a modo de torres y uno rectangular bajo dividido en varios recintos (ver Figura 4). Las investigaciones han comprobado que se trata de un templo asociado a la observación de la salida del sol a lo largo del año, pero

$280 \quad$ Lengua y Sociedad. Revista de Lingüística Teórica y Aplicada 
El término castillo como topónimo de sitios arqueológicos en Perú Alcides R. Alvarez Vera

que en algún momento fue atacado, destruido y abandonado hacia el $300 \mathrm{aC}$., tuvo poco tiempo de uso (Ghezzi 2008, Ghezzi y Rouggles 2011).

Figura 4. El castillo de San Rafael, llamado también Chankillo

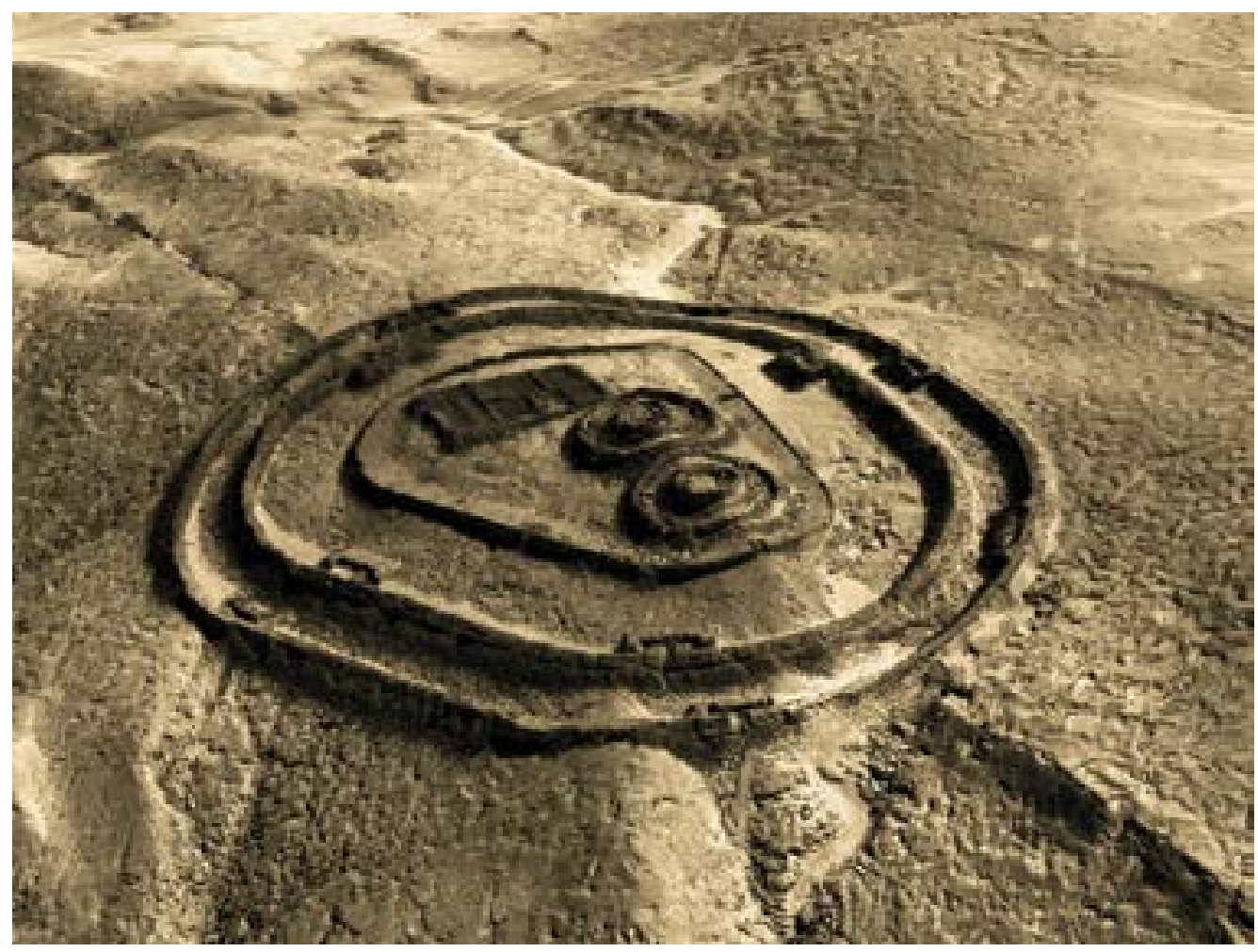

Fuente. Ghezzi, 2008, p. 38.

-Castillo de Huarmey: ubicado en la margen derecha del valle bajo del río Huarmey, conocido desde inicios del siglo xx, un edificio cuadrangular de adobes, de poca altura, construido en la cima de un cerro alargado bajo (ver Figura 5). Los trabajos arqueológicos han revelado que en realidad se trata de mausoleo prehispánico que estuvo en uso durante la época Wari (600 - $1050 \mathrm{dC})$; es decir, no es un edificio militar o de vivienda (Giersz, 2014). 
El término castillo como topónimo de sitios arqueológicos en Perú Alcides R. Alvarez Vera

Figura 5. El castillo de Huarmey

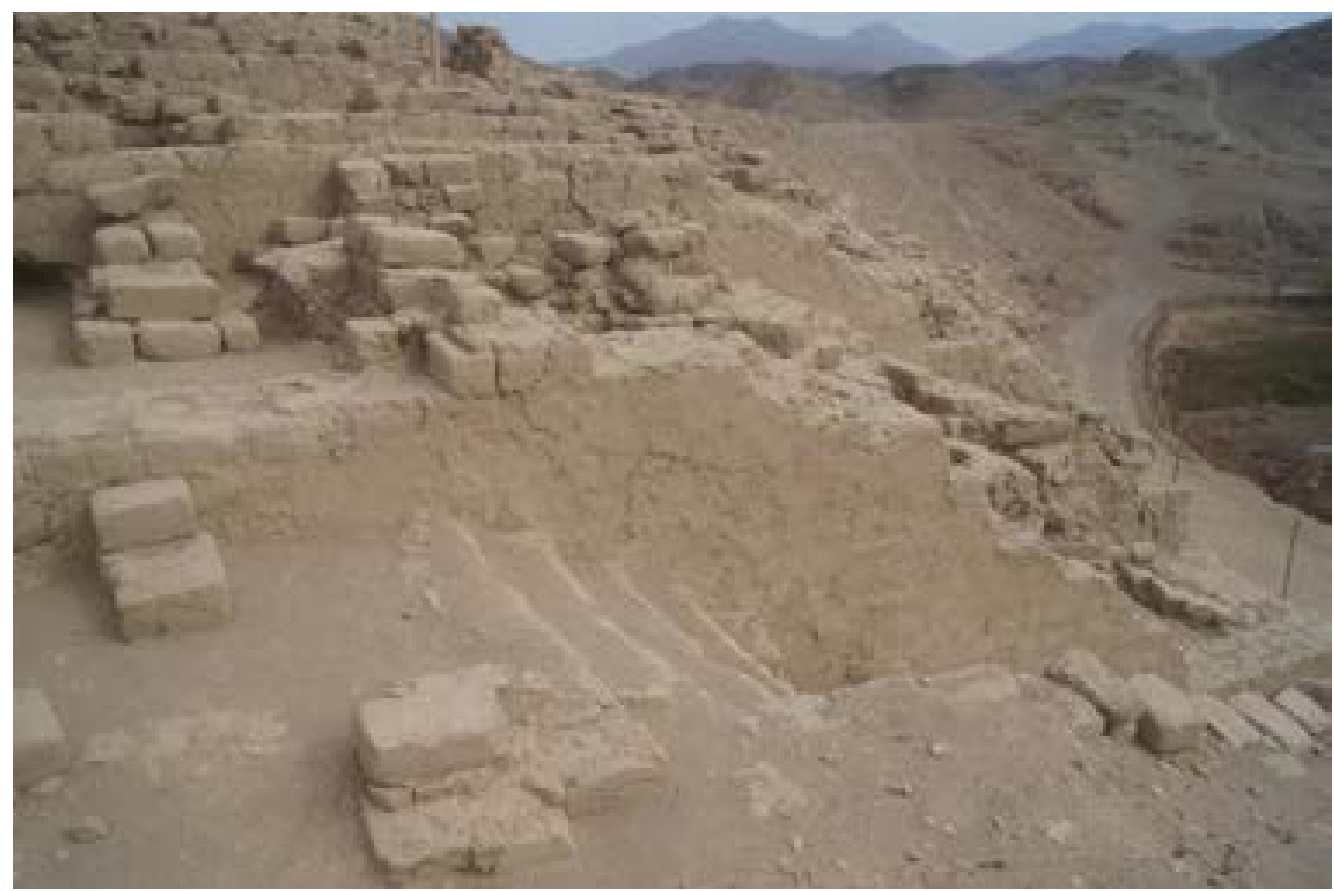

Fotografía del autor.

De igual modo, debido a la metáfora de imagen la palabra castillo se aplicó paralelamente a entidades naturales y no solo a edificaciones prehispánicas, por ejemplo, en el valle arequipeño de Majes tenemos al cerro denominado «El castillo» (Figura 6), cerca de la ciudad de Aplao, que es una unidad geomorfológica de piedra y sedimentos de gran altura y debido a sucesivos desprendimientos asemeja a un grupo de torres al ser al ser observado. 
Figura 6. Cerro El castillo en el valle de Majes

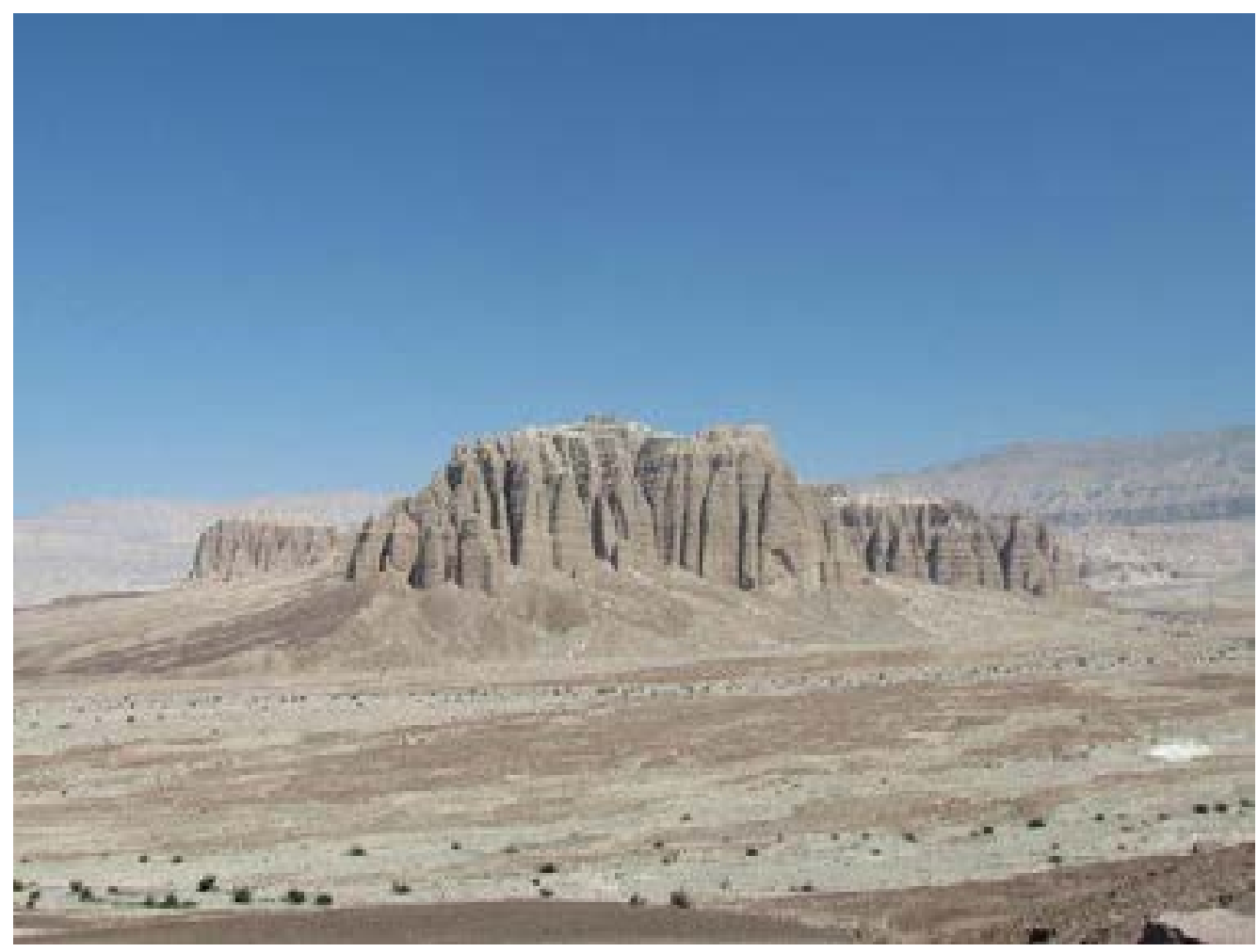

Fuente. Cerro Castillo (2017).

\section{Conclusiones}

Se puede concluir que la causa de la aplicación de la palabra castillo a las edificaciones prehispánicas andinas se debió al uso de la metáfora de imagen desde inicios del periodo colonial por parte de los españoles, y que posteriormente fue continuado por los criollos, mestizos, e indígenas bilingües hasta tiempos republicanos. La forma fue el principal rasgo tomado en cuenta para asignación del nombre castillo el cual pasó luego a denominar el lugar convirtiéndose en topónimo, no hubo castillos en el Perú prehispánico. Como señaló Geeraerts, las metáforas pueden tener fuentes histórica y culturalmente específicas, es decir fuentes que no son universales, sino que se enlazan con una cultura específica y un desarrollo histórico específico (Geeraerts, 2009, p. 220).

Investigaciones interdisciplinarias como esta son necesarias para esclarecer mucha confusión que se originó al aplicarse el léxico español en los Andes 
El término castillo como topónimo de sitios arqueológicos en Perú

Alcides R. Alvarez Vera

centrales desde el siglo XVI, no solo para el caso de la toponimia, sino también para otros aspectos de la vida social, por ejemplo, el de la equivalencia entre escritura y quilca que persiste hasta el presente.

\section{Referencias bibliográficas}

Alatorre, A. (1995). Los 1,001 años de la lengua española. Fondo de Cultura Económica.

Arteguias. (2001). Castillos de España. Características, historia y arquitectura. https://www.arteguias.com/castillos.htm

Barroso, R., Carrobles, J. y Morín, J. (2013). Toponimia altomedieval castrense. Acerca del origen de algunos corónimos de España. e-Spania, revue interdisciplinaire d'études hispaniques médiévales et modernes, 15. https://doi. org/10.4000/e-spania.22501

Bermón, R. S. (2006). Breve historia de los castillos. Isagogé, 3, 60-64. http:// isagoge.atspace.com/documentos/Archivo_isagoge3/BREVE_HISTORIA_DE_ LOS_CASTILLOS.pdf

Bustamante, L. (2001). La Colonia. Colegio de Ingenieros del Perú.

Cabello de Balboa, M. (1951). Miscelánea antártica. Universidad Nacional Mayor de San Marcos.

Cerro Castillo [Fotografía]. (2017). Viajando a Otro Ritmo. https://aotroritmo. files.wordpress.com/2017/04/img_2808.jpg

Cieza de León, P. (1984). Crónica del Perú. Primera parte. Pontificia Universidad Católica del Perú.

Cieza de León, P. (1985). Crónica del Perú. Segunda parte. Pontificia Universidad Católica del Perú.

Cobo, B. (1892). Historia del nuevo mundo. Sociedad de Bibliófilos Andaluces.

Corominas. J. (1987). Breve diccionario etimológico de la lengua castellana. Gredos.

Covarrubias (1611). Tesoro de la lengua castellana. Luis Sánchez.

Cuenca, M. J. y Hilferty, J. (1999). Introducción a la lingüística cognitiva. Ariel.

Evans, V. (2007). A Glossary of Cognitive Linguistics. Edinburgh University.

Fossa, L. (1989). «Pucara»: una clave lingüística para leer a Cieza de León. Boletín de Lima, 64, 45-54.

Geeraerts, D. (2009). Theories of Lexical Semantics. Oxford University.

284 Lengua y Sociedad. Revista de Lingüística Teórica y Aplicada 
Ghezzi, I. (2008). Los primeros tambores de la guerra. En K. Makowski (Comp.), Señores de los reinos de la Luna (pp. 38-53). Banco de Crédito del Perú.

Ghezzi, I. y Rouggles, C. (2011). El observatorio solar más antiguo de América. Investigación y ciencia, 50-58.

Giersz, M. (2014). El hallazgo del mausoleo imperial. En Museo de Arte de Lima (Ed.), Castillo de Huarmey. El mausoleo imperial Wari (pp. 68-99). Mali.

Kostof, S. (1995). A History of Architecture. Oxford University.

Kovecses, Z. y Radden, G. (1998). Metonymy: Developing a Cognitive Linguistic View. Cognitive Linguistic, 9(1), 37-47. https://www.researchgate.net/ publication/270525327_metonymy_developing_a_cognitive_linguistic_view

Lakoff, G. (1987). Image Metaphors. Metaphor and Symbolic Activity, 2(3), 219-222.

Langacker, R. W. (2008). Cognitive Grammar. A Basic Introduction. Oxford University.

Lumbreras, L. G. (2007). Chavín. Excavaciones arqueológicas (Tomo 1). Fondo editorial Universidad Alas Peruanas.

Martínez Ferrer, L. (2017). Tercer concilio límense (1583-1591). Edición bilingüe de los decretos. Facultad de Teología Pontificia y Civil de Lima.

Mayoralgo y Lodo, J. M. (2007). Historia y régimen jurídico de los títulos nobiliarios. Hidalguía. https://cutt.ly/bmVpo8o

Menéndez Pidal, F. (2015). La nobleza en España: ideas, estructuras, historia. Real Academia de la Historia. https://www.boe.es/biblioteca_juridica/abrir_pdf. php?id=PUB-DH-2015-14

Ministerio de Cultura. (2021). Sistema de Información Geográfica de Arqueología. https://sigda.cultura.gob.pe.

Raimondi, A. (1873/2006). El departamento de Ancachs. Universidad Nacional Mayor de San Marcos.

Real Academia Española. (1729). Diccionario de Autoridades (Tomo 2). Autor.

Real Academia Española. (1732). Diccionario de Autoridades (Tomo 3). Autor.

Real Academia Española. (2013). Corpus del Diccionario histórico de la lengua española (CHD; Versión 3.1) [En línea]. https://apps.rae.es/CNDHE

Real Academia Española. (2020a). Castellanía. En Diccionario panhispánico del español jurídico. https://dpej.rae.es/lema/castellan\%c3\%ada

Real Academia Española. (202ob). Castellano. En Diccionario panhispánico del español jurídico. https://dpej.rae.es/lema/castellano

Real Academia Española. (2020c). Castellaria o castellería. En Diccionariopanhispánicodelespañoljurídico.https://dpej.rae.es/lema/castellaria-o-casteller\% $\mathrm{C}_{3} \% \mathrm{ADa}$ 
El término castillo como topónimo de sitios arqueológicos en Perú

Alcides R. Alvarez Vera

Real Academia Española. (2020d). Castillo. En Diccionario de la lengua española [En línea]. https://dle.rae.es/castillo?m=form

Real Academia Española. (2021). Nuevo Tesoro Lexicográfico de la Lengua Española [Base de datos]. http://ntlle.rae.es/ntlle/SrvltguiLoginNtlle

Rivarola, J. L. (1984). Lengua, comunicación e historia del Perú. Boletín de la Academia Peruana de la Lengua, 18, 125-167.

Rivero, M. E. de. (1841/1994). Antiguedades peruanas. Parte primera. En César Coloma Porcari (Ed.), Los inicios de la arqueología peruana (pp. 87-147). Instituto Latinoamericano de Cultura y Desarrollo.

Solís Fonseca, G. (1997). La gente pasa, los nombres quedan. Introducción en la toponimia. CILA-UNMSM.

Subirats Sorrosal, Ch. (2013). El ceremonial militar romano: liturgias, rituales y protocolos en los actos solemnes relativos a la vida y la muerte en el ejército romano del alto imperio [Tesis doctoral, Universitat Autónoma de Barcelona]. Tesis Doctorals en Xarxa. https://www.tdx.cat/bitstream/handle/10803/133339/ css1de1.pdf;sequence $=1$

Tabio, E. (1977). Prehistoria de la Costa del Perú. Instituto de Ciencias Sociales de la Academia de Ciencias de Cuba.

Turismo de Aragón. (s. f.). Castillo de Loarre (Huesca) [Fotografía]. En Sitios de España, Los 10 castillos más bonitos de España. https://www.sitiosdeespana.es/ articulo/los-10-castillos-mas-bonitos-de-espana

\section{Trayectoria académica del autor}

Alcides R. Alvarez Vera es arqueólogo egresado de la Universidad Nacional Mayor de San Marcos, actualmente lleva una maestría en Lingüística en la misma universidad. Ha participado en diversos proyectos de investigación en varios sitios arqueológicos y publicado algunos artículos de su especialidad. Difusor cultural en Lima Este donde ha dado muchas charlas sobre temas diversos. 